\title{
Getting the Balance Right in Intercultural Groups: A Dynamic Social Network Perspective
}

\author{
Bart Rienties ${ }^{1}$, Novie Johan ${ }^{2}$ \\ ${ }^{1}$ Institute of Educational Technology, Open University, Milton Keynes, UK \\ ${ }^{2}$ University of Surrey, Guildford, UK \\ Email: Bart.Rienties@open.ac.uk, n.johan@surrey.ac.uk
}

Received 20 February 2014; revised 27 March 2014; accepted 18 April 2014

Copyright (C 2014 by authors and Scientific Research Publishing Inc.

This work is licensed under the Creative Commons Attribution International License (CC BY). http://creativecommons.org/licenses/by/4.0/

(c) (i) Open Access

\begin{abstract}
Problem: A common assumption is that students prefer to select their friends for group-work. The prime goal of this study was to understand the impact of two group selection methods on how students from diverse cultural backgrounds build learning and work relations. Method: Social Network Analysis in a pre-post test manner in a quasi-experimental design of 81 vs. 70 third-year students. Solution: In this study, we "disrupted" this group selection process after Day 1 by balancing students from different parts of the social network together. In one condition the students were "balanced" into groups by staff to encourage structural hole formation, and in the other condition students were allowed to self-select their group members to encourage network closure. Results: Students in the self-selected condition primarily selected their friends from a similar cultural background. In both conditions the learning networks after 11 weeks were primarily predicted by the group allocation and initial friendships. However, students in the balanced condition developed more cross-cultural learning links. These results indicate that teachers can actively intervene in the cross-cultural dynamics in- and outside the classroom.
\end{abstract}

\section{Keywords}

Social Network Analysis, Cross-Cultural Learning, Quasi-Experimental Study, Structural Hole vs Network Closure

\section{Introduction}

Recent research indicates that students seem to prefer to develop social network relations with students from 
similar cultural backgrounds [1] [2]. When students are allowed to self-select their group members, most students select their friends and co-national students [3]-[5]. According to Chapman, Meuter, Toy and Wright [6], self-selection is a preferred group allocation method, as students prefer to work together with friends in groups and its leads to more trust and knowledge co-construction. While self-selection might encourage trust amongst its members, the obvious risk is cronyism. Although a large body of literature indicates that being able to work effectively with new individuals in mixed (cultural) groups is a key graduate skill [5] [7] [8], many students are reluctant to embrace mixed group work due to difficulties with cross-cultural collaboration [9] [10], difficult group dynamics [11], and risk of grade inflation when working with (perceived) "less-able" international students [5] [12].

When teachers create mixed groups, students from different cultural backgrounds are "forced" to work together. This might lead to stress and anxiety for some, but at the same time creates opportunities to learn from different cultural and individual perspectives [1] [8] [13] and allows group members to obtain new, non-redundant information from different parts of the network [14] [15]. Mixed group work may allow host and international students to build cross-cultural social network relations. Furthermore, students may benefit from establishing cross-cultural relations in the form of new and diverse social capital links to future connectors and leaders abroad.

Recently, several studies [1] [4] [10] [16]-[18] using social network analysis (SNA) have become available to understand how international and host students develop and maintain social relations. However, in most SNA studies the focus of study is either on the ego [16], the group [8] [17], or an international programme as a whole [1] [16], thereby potentially missing vital informal and formal interactions between students and groups in a module.

The prime goal of this dynamic social network analysis study [10] [18]-[20] is to understand whether teachers, by means of an instructional design intervention, can actively encourage and intervene in cross-cultural learning by adjusting the group selection method. In the experimental condition, dyads or triads of friends from different parts of the network were merged into groups in order to increase the diversity of network links, in line with ideas of structural holes of Burt [14]. In the control condition, students were allowed to self-select their members in order to create closely knit groups/clusters, in line with network closure concepts of Coleman [21]. In this quasi-experimental study with 151 third year undergraduate students using pre-post Social Network Analysis, we compared how students from different cultural backgrounds, over time, built and developed social relations.

\section{Social Capital, Structural Holes and Group-Learning}

Social capital can be defined as "resources embedded in a social structure which are accessed and/or mobilized in purposive action" [22]. In social network research, often a distinction is made between structural holes [14] and network closure [21] in how people build social connections and maintain interpersonal relationships in order to benefit from social capital within those relations. Burt [14] argues that individuals will gain more from social networks if they are able to position themselves on either side of a bridge between two "groups" or clusters of people. A bridge can be seen as a structural hole in the social networks [19] [23]-[25], which may provide non-redundant information from different parts of the social network. In contrast, Coleman [21] indicates that high levels of connectedness between people can encourage formation of trust and stable relations [11] [26], which in turn enhances fine-grained knowledge sharing and performance.

Putnam [27] distinguishes between bonding and bridging social capital, whereby bonding social capital provides solidarity, mutual reinforcement and support, while bridging social capital provides linkages with different (non-redundant) parts of the social network, thereby facilitating social mobility and potentially social inclusion [27]. In an international classroom, commonly bonding capital is found amongst international students who share a similar transitional cross-cultural experience. At the same time, new bridging capital could be created when students from different cultural backgrounds are able to develop new cross-cultural social network relations [28].

Nonetheless, previous research has shown that establishing cross-cultural friendship relations is difficult for international and host students, given language and cultural issues [9] [10], and most host students already have well-established friendship networks [1]. If mixed groups are able to overcome their initial differences and potential conflicts, research [11] [17] indicates that mixed groups are more able to come up with creative solutions and insights in comparison to mono-cultural groups. Indeed our own research [4] [10] [18] [29] indicates that 
when students work on "authentic and complex" group products for a substantial period of time and are summatively assessed (i.e. receive a group grade), international and host students are able to develop strong social network relations.

In a longitudinal study amongst 485 international and 107 host students in three years of undergraduate and one year of postgraduate business education, Rienties and Nolan [18] found that the primary predictor of learning networks after 11 weeks for four out of five modules was how students were enrolled into groups. Although cultural variables influenced initial social networks, across all four years when students were put into mixed groups and worked on authentic complex tasks these cultural factors diminished in importance. In a follow-up quasi-experimental study [5] to better understand how group-selection methods [6] influence learning dynamics over time amongst 138 post-graduate business students, students in the randomised condition of mixed cultural groups performed equally well as self-selected groups on three group products. At the same time, students in the randomised condition maintained more links to students outside their group (i.e., inter-group links), which encouraged non-redundant information sharing across groups [5]. Most importantly, in the randomised condition students developed strong intercultural links, while in the self-selected condition most students continued to learn with students from similar cultural backgrounds. However, a major limitation of this study was that the low number of host students (4\%) and the clear need to work together in groups (due the fact that $80 \%$ of the course grade was determined by group work). In most educational contexts, the balance between host and international students is more equal and the vast majority of grading is focused on individual contributions.

Irrespective of the group allocation, students will most likely continue to share their experiences with their friends, even when they were allocated in different groups [15] [30]. As argued by Hernandez Nanclares, Rienties and Van den Bossche [20], students may develop knowledge spillovers between groups, whereby students from different groups formally and informally share ideas and constructs developed with their respective group, thereby potentially increasing the knowledge and expertise across groups. In several organizational studies [23] [25] [29], it is highlighted that a combination of strong local ties (network closure) with sufficient "external" network links (structural holes) leads to better performance. For example, Giuliani [29] found that when wine producers are locally embedded, they are more likely to develop successful products. However, firms with relatively more external openness outperform firms that are only locally embedded. As argued by Reagans and McEvily [24], "an optimal network combines elements of cohesion and range... The most productive teams are internally cohesive, but have external networks full of structural holes".

In this quasi-experimental study, in the experimental condition we tried to balance the (potentially] opposite effects of bonding and bridging social capital, or network closure and structural holes, by artificially creating balanced groups based upon students' initial social network. In other words, after measurement of the friendship network at Day 1, in each group we enrolled dyads or triads of friends from different part of the social network in order to create a sufficiently diverse group with limited redundant links, in line with the structural hole concept of Burt [14]. At the same time, each student had at least one friend within his/her group, thereby encouraging familiarity and trust [11] [21] [26].

In the control condition, students were allowed to self-select their members of their group, as recommended by Chapman, Meuter, Toy and Wright [6]. Therefore, in line with Rienties, Alcott and Jindal-Snape [5] we expected that students in the self-selected-condition would select group members based upon prior friendships and co-nationality (H1). As a result, we expected that in comparison to the self-selected condition in the experimental condition groups were more culturally diverse due to the balancing of the groups (H2). After eleven weeks, we expected that students in the self-selected condition primarily maintained learning links with students from similar cultural backgrounds, while in the balanced (experimental) condition cultural backgrounds were no longer important (H3). Even if no formal summative assessment of group products was present, in line with previous findings [5] we expected that group enrolments had a significant influence on social network interactions (H4). Finally, we expected that more knowledge spillovers were maintained in the balanced condition, as more "potential" structural holes were generated by mixing different parts of the network together (H5). In other words, the following hypotheses are tested:

H1: Self-selected groups are constructed based upon (prior) friendships.

$\mathrm{H} 2$ : Balanced groups are more culturally diverse than self-selected groups.

H3: Only in the self-selected condition is the development of social learning networks over time related to the similarity of cultural backgrounds.

H4: The development of social learning networks over time is related to the group allocation for both balanced and self-selected condition. 
H5: In comparison to the self-selected condition, students maintain more learning relations outside their group in the balanced condition.

\section{Methods}

\subsection{Procedure}

This study took place in a third year undergraduate programme of hospitality and tourism management at a British university in the spring semesters of 2012 and 2013. In this quasi-experimental study, the implementation of 2012 is referred to as the "balanced condition", while the implementation of 2013 is referred to as the "self-selection condition". In 2012, the teacher balanced the groups based upon the social network obtained after Day 1. In 2013, students were able to self-select their members of the group on the first day of the module.

\subsection{Setting}

In the experimental (balanced) condition, after the first measurement of social friendship network, students were put into "balanced" groups based upon their social network position. Based upon the visualisation of the friendship network using Netdraw, one of the authors mixed dyads and triads of students from different parts of the social network together. As a result, 10 small working groups were formed in Week 2 in the balanced condition, with an average group size of $8.10(\mathrm{SD}=0.74)$. In the control (self-selected) condition, students at Day 1 could indicate their preference of working in a particular group, with an average group size of $5.83(\mathrm{SD}=0.94)$. During the course, students met formally once a week during a three-hour interactive lecture alongside (online/faceto-face) informal meetings with the peers of their group, whereby they worked on weekly tasks. These group products were not summatively assessed but the teacher provided formative feedback. A detailed description of the design principles of the module and how the students were balanced has been published elsewhere [28]. Except for the group selection method (i.e. balanced vs. self-selection), the assessments, module materials and the teacher were the same in both conditions.

\subsection{Participants}

81 and 70 students registered for the module respectively and all 151 students were included in our analyses. The division of participants for each group/condition based upon the GLOBE categorisation of House, Hanges, Javidan, Dorfman and Gupta [31] is illustrated in Table 1, whereby the largest group of students were from Confucian Asia (51\%), followed by Anglo-Saxon (26\%), Eastern Europe (16\%), Latin Europe and Southern Asia (both 4\%), Sub-Saharan Africa (3\%), Germanic Europe (2\%) and Latin America (1\%). In the balanced condition, 10 groups were created by the teacher, while in the self-selected condition 12 groups were "created" by the students. $120(79 \%)$ participants were female and the average age was $23.13(\mathrm{SD}=2.51)$.

\subsection{Measuring Friendship, Working and Learning Networks}

Numerous researchers have found that SNA networks provide robust and accurate depictions of actual learning processes and social networks [19] [30], and recent research highlights that social networks are the key predictor for learning [30] [32]. Pre-existing social relations were measured using closed-network analyses [10], whereby during the first session a list with all respective names of the students was provided and the 151 students answered three Social Network questions, namely "I am a friend of...", "I have learned a lot from..." and "I have worked a lot with...". At Week 11, we again measured these social networks in order to analyse whether the dynamics of inter-and intra-group learning of the students had changed. For the two measurements a response rate of $83 \%$ and $67 \%$ was established for the balanced condition, and $84 \%$ and $86 \%$ for the self-selected condition respectively.

\subsection{Data Analysis}

As a first step to ensure that the two cohorts were comparable at the pre-test, we analysed the division of nationalities present, gender, academic performance during the year, and age, whereby we used Chi-Squares for categorical values and ANOVAs for binominal values. No significant differences were found between the two 
Table 1. Division of groups based upon cultural background (GLOBE).

\begin{tabular}{|c|c|c|c|c|c|c|c|c|c|c|c|c|c|}
\hline Balanced Selection & Group 1 & Group 2 & Group 3 & Group 4 & Group 5 & Group 6 & Group 7 & Group 8 & Group 9 & $\begin{array}{c}\text { Group } \\
10\end{array}$ & $\begin{array}{c}\text { Group } \\
11\end{array}$ & $\begin{array}{c}\text { Group } \\
12\end{array}$ & Total \\
\hline Anglo-Saxon & 6 & 0 & 4 & 0 & 0 & 2 & 3 & 3 & 2 & 2 & & & 22 \\
\hline Latin Europe & 0 & 1 & 0 & 0 & 1 & 0 & 0 & 1 & 1 & 0 & & & 4 \\
\hline Germanic Europe & 0 & 0 & 0 & 0 & 0 & 2 & 0 & 0 & 0 & 1 & & & 3 \\
\hline Eastern Europe & 0 & 3 & 0 & 0 & 1 & 2 & 2 & 3 & 1 & 2 & & & 14 \\
\hline Latin America & 0 & 0 & 0 & 0 & 0 & 0 & 1 & 0 & 0 & 0 & & & 1 \\
\hline $\begin{array}{l}\text { Sub-Saharan } \\
\text { Africa }\end{array}$ & 1 & 2 & 0 & 0 & 0 & 0 & 0 & 0 & 0 & 1 & & & 4 \\
\hline Southern Asia & 0 & 0 & 1 & 0 & 0 & 0 & 0 & 1 & 0 & 0 & & & 2 \\
\hline Confucian Asia & 1 & 2 & 3 & 8 & 5 & 4 & 2 & 0 & 4 & 2 & & & 31 \\
\hline Self-selection & Group 1 & Group 2 & Group 3 & Group 4 & Group 5 & Group 6 & Group 7 & Group 8 & Group 9 & $\begin{array}{c}\text { Group } \\
10\end{array}$ & $\begin{array}{c}\text { Group } \\
11\end{array}$ & $\begin{array}{l}\text { Group } \\
12\end{array}$ & Total \\
\hline Anglo-Saxon & 2 & 6 & 4 & 0 & 0 & 2 & 2 & 0 & 0 & 0 & 1 & 0 & 17 \\
\hline Latin Europe & 0 & 0 & 0 & 0 & 0 & 0 & 1 & 0 & 0 & 0 & 1 & 0 & 2 \\
\hline Germanic Europe & 0 & 0 & 0 & 0 & 0 & 0 & 0 & 0 & 0 & 0 & 0 & 0 & 0 \\
\hline Eastern Europe & 1 & 0 & 1 & 1 & 0 & 1 & 4 & 0 & 0 & 1 & 1 & 0 & 10 \\
\hline Latin America & 1 & 0 & 0 & 0 & 0 & 0 & 0 & 0 & 0 & 0 & 0 & 0 & 1 \\
\hline $\begin{array}{l}\text { Sub-Saharan } \\
\text { Africa }\end{array}$ & 0 & 0 & 0 & 0 & 0 & 0 & 0 & 0 & 0 & 0 & 0 & 0 & 0 \\
\hline Southern Asia & 0 & 0 & 0 & 1 & 0 & 0 & 0 & 3 & 0 & 0 & 0 & 0 & 4 \\
\hline Confucian Asia & 2 & 0 & 1 & 4 & 6 & 3 & 0 & 3 & 6 & 5 & 0 & 6 & 36 \\
\hline
\end{tabular}

conditions. As a second step, graphical analyses of the social networks were conducted in order to identify the overall social network structure and to identify possible patterns of sub-group development [33]. Third, in line with Rienties, Hernandez Nanclares, Jindal-Snape and Alcott [10] for both cohorts we constructed a GLOBE matrix, whereby we clustered students based upon their geocultural region classification [31]. Furthermore, we controlled for gender, students' respective specialisation and group allocation.

Fourth, we determined the position of each student within their group (intra] relative to other students (inter] in the social learning network using the External-Internal index [34]. Basically, the E-I index takes the number of ties of members of the group to students outside the group, subtracts the number of ties to members within the group, and divides this by the total number of ties. The resulting index ranges from " -1 " (all ties are only with own group members) to " +1 " (all ties are to students outside the group). Finally, multiple regression quadratic assignment procedures (MRQAP) were used to test whether pre-existing friendship and working relations amongst students and group allocation predicted social learning networks after 11 weeks. Data were analysed on a network level using UCINET version 6.445.

\section{Results}

\subsection{Visualisation of Social Networks}

In Figures 1-4, the learning networks at the beginning and end of both conditions are illustrated, whereby three main trends are visually present. Please note that Netdraw positions nodes at random across the $\mathrm{X}$ - and $\mathrm{Y}$-axis based upon the (perceived) social interactions between students, whereby students who share similar connections are positioned more closely together. Being on the left of a social learning graph is not necessarily better or worse than being on the right, top or bottom, but students with similar learning connections are positioned closer together. First, a large group of Confucian Asian students (blue, diamond) formed a highly linked subgroup on the left of Figure 1 and right of Figure 2. The shape and colour of the nodes refers to students' respective 


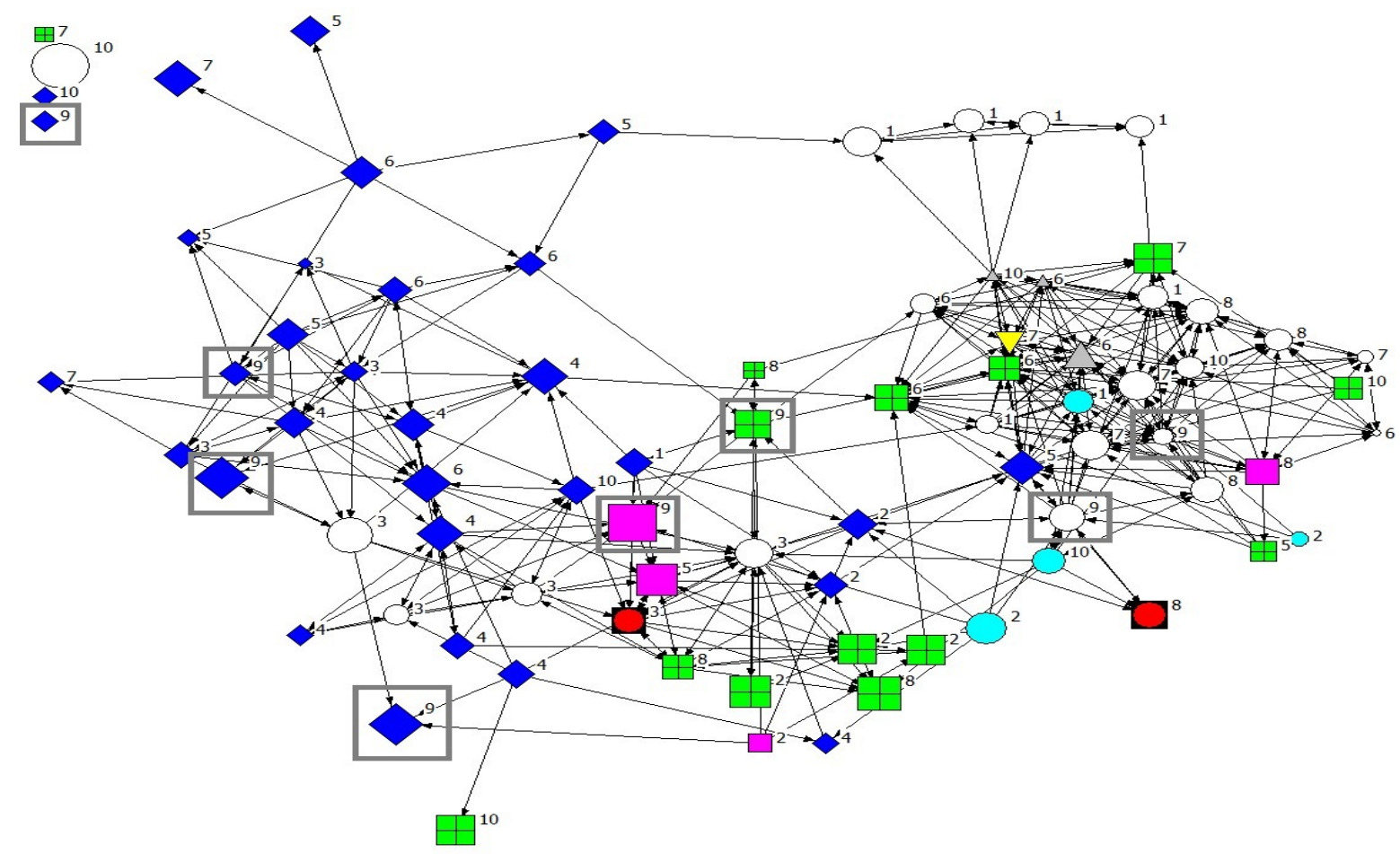

Figure 1. Social learning network at the start of balanced condition. Note: Group numbers are illustrated above each node. Furthermore, the shape and colour of each node is based upon GLOBE: Anglo-Saxon (white, circle); Latin Europe (pink, square); Germanic Europe (grey, up triangle); Eastern Europe (light green, box); Sub-Saharan Africa (light blue, circle); Middle East (yellow, down triangle); Southern Asia (red circle in black box); Confucian Asia (blue, diamond).

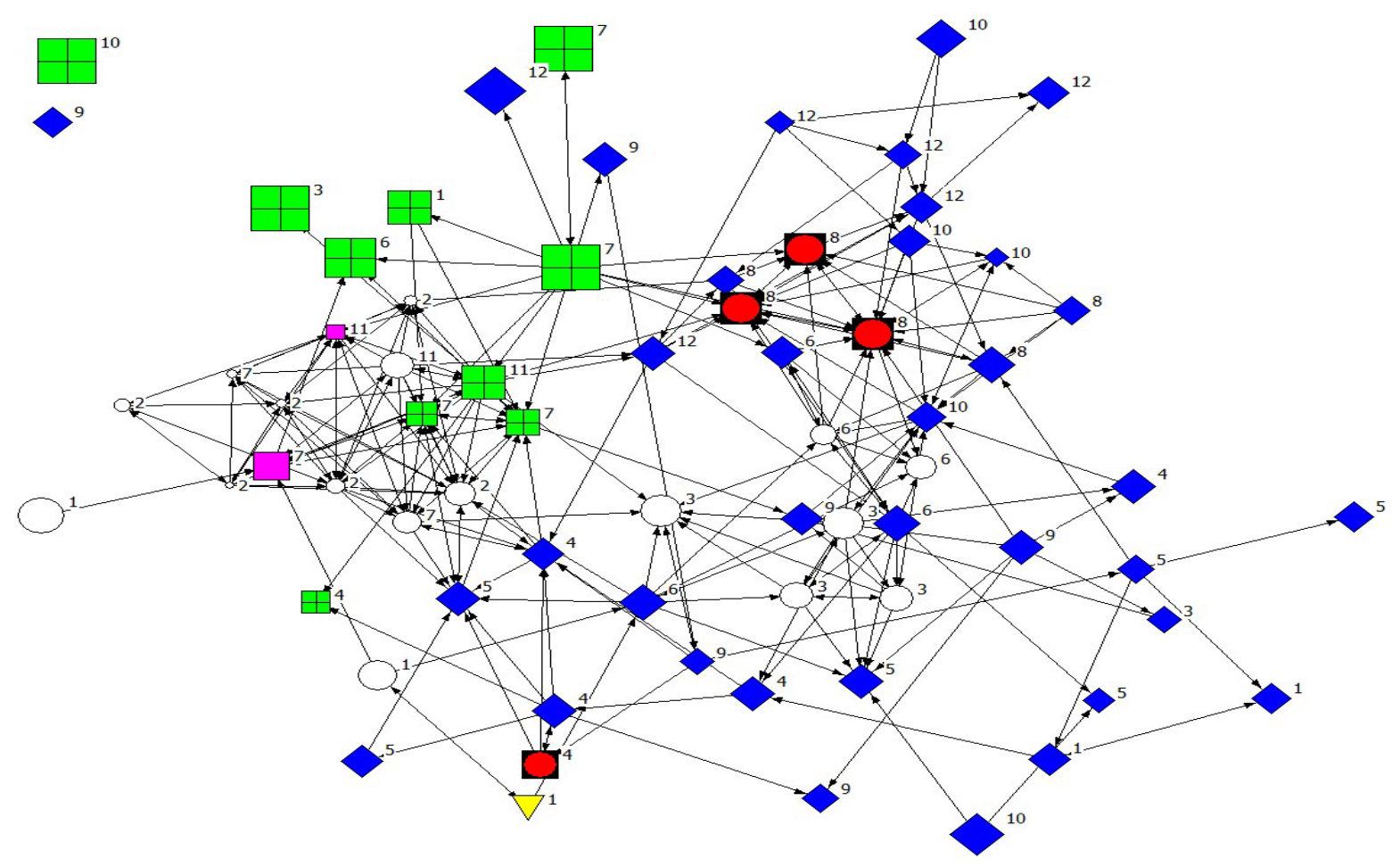

Figure 2. Social learn network at the start of self-selected condition. 


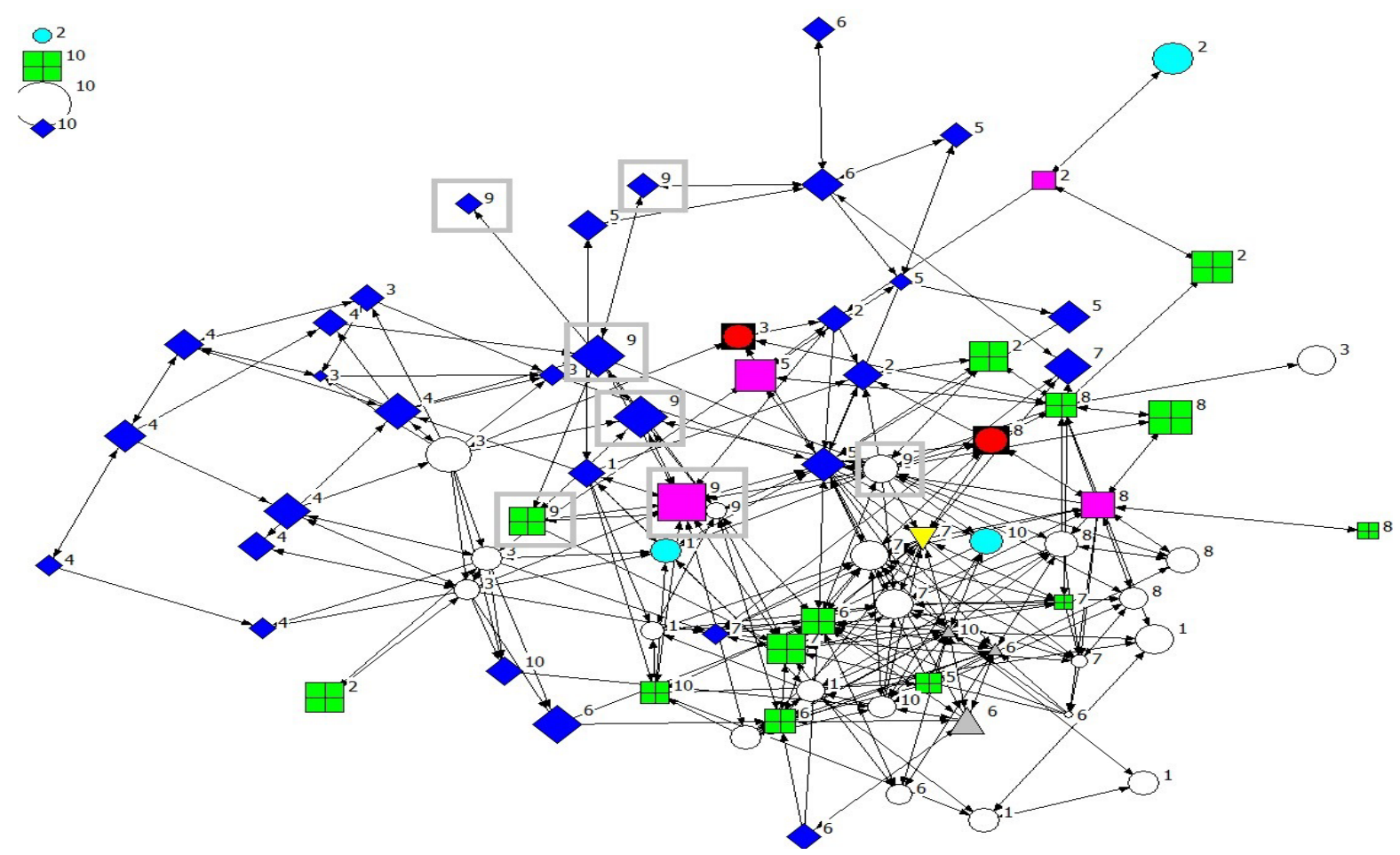

Figure 3. Social learning network of balanced condition after eleven weeks.

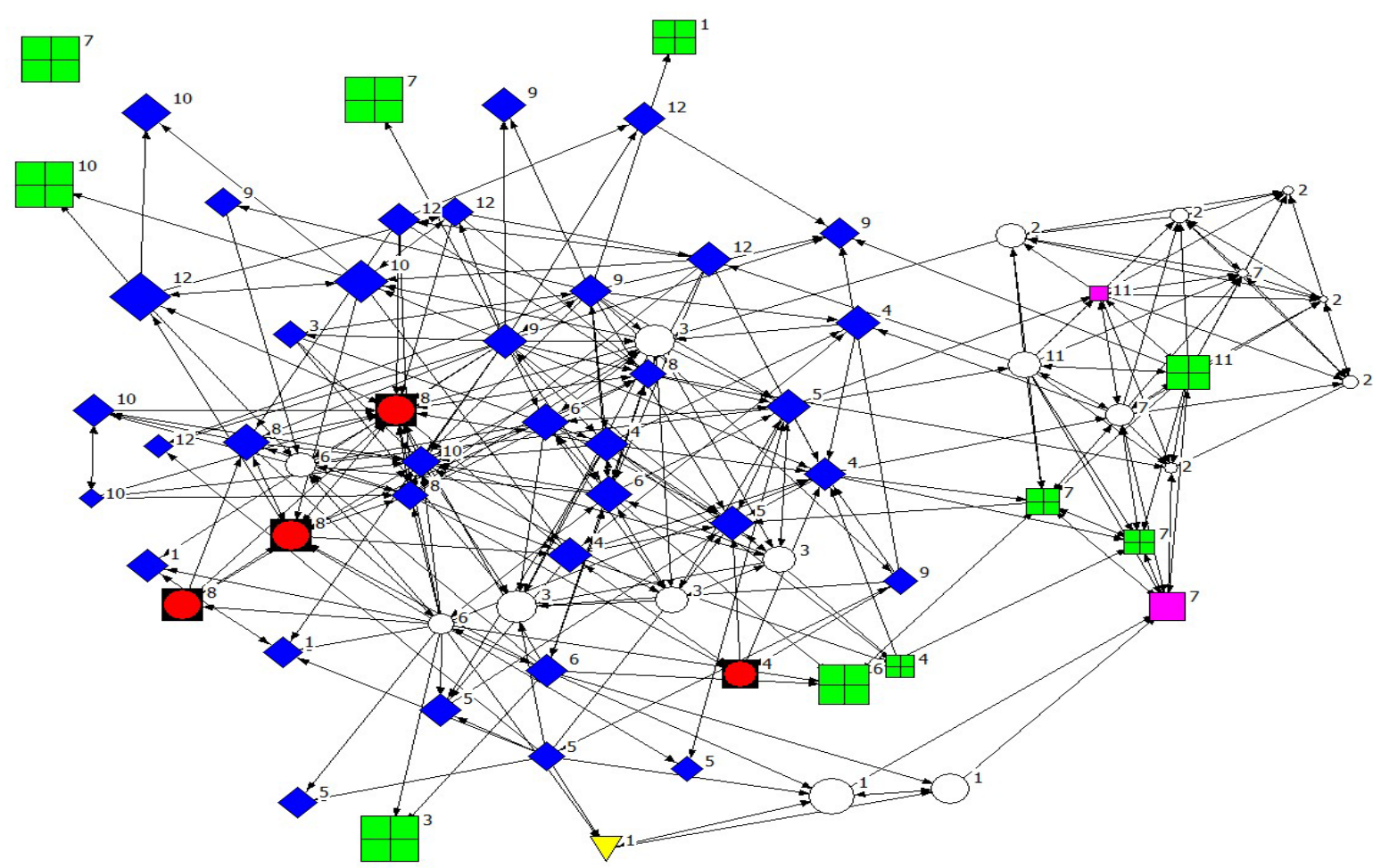

Figure 4. Social learning network of self-selection condition after eleven weeks.

GLOBE culture, while the size of the node is based upon the structural hole efficiency index of Burt [14], which is the effective size divided by the number of alters in ego's network as computed on the initial friendship net- 
work. Most English and Western international students were positioned away from Confucian Asian students, which was previously found in other settings [4] [10].

Second, as students were balanced in groups in Figure 1, students from various parts of the social network were "forced" to work together [28]. For example, four Confucian Asian, who were positioned on the left [i.e. labels refer to group numbers], were enrolled in group 9 with two international students and two host students on the middle and right of Figure 1 (as illustrated by the grey boxes around these eight nodes]. Four Confucian Asian members of group 6 were positioned on the top left, while a mix of four Western international students and one host student were positioned on top right were enrolled in group 6 [28]. In contrast, most neighbours of students in the self-selected condition had the same group number (e.g., group 8 or group 12 on the right of Figure 2), indicating that most students selected group members from their "neighbourhood" of learning buddies.

Third, several students in the balanced condition developed substantial new learning links with their assigned group members over time, as illustrated in Figure 3. For example, while in Figure 1 the Confucian Asian students from group 9 were initially located in a different part of the social network in comparison to the host and Western international students, all members of group 9 were (in) directly connected to each other in the middle and top of Figure 3 (as illustrated by the grey boxes around these eight nodes). In contrast, group 6 remained to consist of two sub-networks, whereby two out of three Confucian Asian students remained in a separate part of the network (top of Figure 3), while one Confucian Asian student developed learning links with most other members of group 6 on the bottom of Figure 3. As one would expect, in the self-selected condition most students developed learning relations with their selected group members, and respective group structures were (relatively) more visible in the self-selected condition in Figure 4.

\subsection{Comparison of Internal and External Group Friendships, Culture and Learning}

Although the above visualisation gives a first impression of the data, quantitative analyses are needed in order to determine whether (or not) the two group allocation methods influenced inter-intra-group learning. As indicated in Table 2, students in the self-selected condition had significantly more friends (Mean $=3.00$, Standard Devia tion = 1.45) in their group than in the balanced condition $(\mathrm{M}=1.63, \mathrm{SD}=1.32)$ at the pre-test. Furthermore, the E-I index for the balanced condition was significantly higher $(\mathrm{M}=0.66, \mathrm{SD}=0.32)$ than the self-selected condition $(\mathrm{M}=0.48, \mathrm{SD}=0.27)$, indicating that the majority of friendship relations were outside their group (H1), with effect sizes that were strong in size. The number of students within the group with a different cultural background (4.77) was significantly higher in the balanced condition in comparison to the self-selected condition (2.09), with a moderately strong effect size. The E-I index of the self-selected condition was significantly

Table 2. Friendship, GLOBE and learning links within and outside groups (balanced vs. self-selected condition).

\begin{tabular}{|c|c|c|c|c|c|c|}
\hline & \multicolumn{2}{|c|}{ Balanced } & \multicolumn{2}{|c|}{ Self-selected } & \multirow[b]{2}{*}{ F-value } & \multirow[b]{2}{*}{$\eta 2$} \\
\hline & M & $\mathrm{SD}$ & M & $\mathrm{SD}$ & & \\
\hline \multicolumn{7}{|l|}{ During the first week } \\
\hline Friendship relations within group & 1.63 & 1.32 & 3.00 & 1.45 & $36.880^{* *}$ & 0.20 \\
\hline Friendship relations outside group & 8.57 & 5.26 & 9.54 & 5.00 & 1.349 & 0.01 \\
\hline E-I friendship relations & 0.66 & 0.32 & 0.48 & 0.27 & $13.496^{* *}$ & 0.08 \\
\hline Same GLOBE relations within group & 2.40 & 2.08 & 2.89 & 1.90 & 2.258 & 0.02 \\
\hline Different GLOBE relations within group & 4.77 & 2.30 & 2.09 & 1.88 & $60.322^{* *}$ & 0.29 \\
\hline E-I GLOBE relations within group & 0.32 & 0.61 & -0.14 & 0.76 & $16.898^{* *}$ & 0.10 \\
\hline \multicolumn{7}{|l|}{ After 11 weeks } \\
\hline Learning relations within group & 2.72 & 1.98 & 2.49 & 1.35 & 0.678 & 0.01 \\
\hline Learning relations outside group & 3.58 & 3.64 & 5.23 & 3.86 & $7.294^{* *}$ & 0.05 \\
\hline E-I index learning relations & 0.01 & 0.54 & 0.29 & 0.36 & $13.781^{* *}$ & 0.08 \\
\hline
\end{tabular}

ANOVA of Balanced $(\mathrm{n}=81)$ vs. self-selected condition $(\mathrm{n}=70) . * * \mathrm{p}<.01, * \mathrm{p}<.05$. 
more focused on similar GLOBE backgrounds $(-0.14)$ in comparison to the balanced condition $(0.32)$, providing support for H2. In other words, in line with our expectations students in the self-selected condition chose students from similar cultural backgrounds, while the "balancing" of students from different networks in the experimental condition led to more culturally diverse groups.

In contrast to previous findings [5], students in the balanced condition did not develop and maintain more learning links outside the group over time, thereby providing no support for H5. While slightly more learning links within the group were developed in the balanced condition (though not statistically significant), students in the self-selected condition maintained significantly more total learning links and were significantly more outward focused in terms of E-I index.

\subsection{MRQAP Regressions}

In Table 3, MRQAP results of learning ties after eleven weeks for the balanced and self-selected condition are illustrated, each estimated by three models. In all six models gender did not significantly predict learning, while the specialisation students were enrolled into was a consistent significant predictor, though small in size. Learning ties in the balanced condition were significantly predicted by cultural backgrounds in Model 1. Adding group allocation significantly improved the fit of Model 2, and 10\% of variance was explained by the (balanced) group allocation, providing initial support for H4. Finally, adding initial friendships and initial working relations to Model 3 added $10 \%$ additional explained variance. Cultural backgrounds no longer significantly predicted learning after eleven weeks in Model 2 and Model 3. Group allocation was the strongest predictor for learning after eleven weeks. Subsequent MRQAPs indicated that working relations after eleven weeks (not illustrated) were primarily predicted by the group allocation $(\beta=0.43 ; \mathrm{p}<0.01)$, followed by initial work ties $(\beta=0.24 ; \mathrm{p}$ $<.01)$ and initial friendship ties $(\beta=0.09 ; \mathrm{p}<0.01)$, with an adjusted R-square of 0.31 . Friendship relations after eleven weeks were primarily predicted by initial friendship ties $(\beta=0.36 ; \mathrm{p}<0.01)$, followed by the group allocation $(\beta=0.23 ; \mathrm{p}<0.01)$ and initial work $(\beta=0.09 ; \mathrm{p}<0.05)$, with an adjusted $\mathrm{R}$-square of 0.25 .

For the self-selected condition, learning ties were significantly predicted by cultural backgrounds in Model 4 . Adding the group allocation in Model 5 improved the fit and 10\% of the variance was explained (H4), but cultural backgrounds remained a significant predictor of learning networks (H3). Finally, adding initial friendships and working relations to Model 6 added 15\% additional variance, whereby initial work primarily predicted learning networks. Subsequent MRQAPs indicated that work relations after eleven weeks (not illustrated) again were primarily predicted by initial work ties $(\beta=0.37 ; \mathrm{p}<0.01)$, followed by the group allocation $(\beta=0.27 ; \mathrm{p}<$ $0.01)$, initial friendship ties $(\beta=0.09 ; \mathrm{p}<0.01)$, and similar cultural background $(\beta=0.05 ; \mathrm{p}<0.01)$, with an adjusted R-square of 0.34 . Friendship relations after eleven weeks were primarily predicted by initial friendship ties $(\beta=0.57 ; \mathrm{p}<0.01)$, followed by the group allocation $(\beta=0.11 ; \mathrm{p}<0.01)$ and similar cultural background $(\beta$ $=0.09 ; \mathrm{p}<0.01$ ), with an adjusted R-square of 0.44 . In other words, in the self-selected condition cultural backgrounds of students remained an important predictor for social networks after eleven weeks, while in the balanced condition this was no longer important (H3). The main effects of this study are summarised in Figure 5,

Table 3. Multiple regression quadratic assignment procedures of learning after eleven weeks (standardised betas).

\begin{tabular}{|c|c|c|c|c|c|c|}
\hline & \multicolumn{3}{|c|}{ Balanced condition } & \multicolumn{3}{|c|}{$\underline{\text { Self-selected condition }}$} \\
\hline & Model 1 & Model 2 & Model 3 & Model 4 & Model 5 & Model 6 \\
\hline Gender & -0.000 & -0.000 & -0.004 & -0.027 & -0.030 & -0.019 \\
\hline Specialisation & $0.071^{* *}$ & $0.052^{* *}$ & $0.026^{*}$ & $0.061^{*}$ & $0.056^{* *}$ & $0.023^{*}$ \\
\hline GLOBE & $0.048^{*}$ & 0.029 & -0.024 & $0.100^{* *}$ & $0.060^{*}$ & 0.012 \\
\hline Group allocation & & $0.311^{* *}$ & $0.284^{* *}$ & & $0.291^{* *}$ & $0.156^{* *}$ \\
\hline Initial Friendship & & & $0.160^{* *}$ & & & $0.229^{* *}$ \\
\hline Initial Work & & & $0.200^{* *}$ & & & $0.257^{* *}$ \\
\hline $\mathrm{R}^{2}$ adj. & $0 \%$ & $10 \%$ & $20 \%$ & $1 \%$ & $10 \%$ & $25 \%$ \\
\hline
\end{tabular}


where by students in the balanced condition over time became more externally focused (i.e., both E-I indexes were higher at the post-test M2 and above zero) in terms of the cross-cultural learning and friendship networks. While learning networks in the self-selected condition were slightly more externally focused towards cross-cultural learning relations over time on the left of Figure 5, the friendship networks became more internally focused on students with similar cultural backgrounds (i.e., the E-I index became significantly more negative).

\section{Discussion and Conclusion}

In this quasi-experimental study amongst 151 third year hospitality students, our study indicates that instructional design and the method of group allocation in particular can have a substantial impact on how students develop cross-cultural, inter- and intra-group learning relations. In contrast to the balanced condition, in the self-selected condition cultural backgrounds remained a significant predictor for learning, working and friendships network after 11 weeks. That is, when "forced" to work together in groups for a substantial period of time, only students in the balanced condition seemed able to overcome some of the initial cultural barriers that prevented students to learn together in mixed groups. By balancing students from different parts of the social network in order to encourage (potential) structural hole formations [14], several groups became well-connected "teams" and effectively worked and learned together over time, despite the fact that originally these sub-group networks were not connected.

In contrast to previous findings [5], significantly more knowledge spillovers were generated in the self-selected condition than in the balanced condition. Two possible explanations might be provided for this lack of support of H5. First, as group work was not summatively assessed (i.e., not graded) in this context, perhaps the necessity to work together as a group was lower. This may have resulted in lower stimulations or pressures to create (high quality) group products, and to informally compare (drafts of) results with other groups (of trusted friends). Second, the relatively lower response rate in the balanced condition might have influenced the (non-reported) social network links.

Nonetheless, in the balanced condition more cross-cultural learning and friendship links were established in comparison to the self-selected condition, which was the primary purpose of our intervention. This is particular important as preliminary findings indicate that bridging cross-cultural differences becomes more difficult over time. Our longitudinal study [18], whereby the balanced condition was included in the data analyses, and research by Summers and Volet [3] indicated that while in the first year of study students seem very willing to share learning experiences with students from different cultures, over time international student and in particular the Confucian Asian students seemed to form a separate learning group. The self-selected condition seemed to have strengthened this effect, as in particular for the friendship networks a more internal focus over time was found. In other words, the way teachers allocate students to groups can have a strong impact how students develop intra-group and inter-group social relations. In contrast to recommendations of Chapman, Meuter, Toy and Wright [6], our previous study [5] and this study seem to indicate that although self-select might (initially) encourage more trust and support within groups, students seem less willing to bridge cultural differences typically present in most contemporary international classrooms. Therefore, the preferred method of self-selection of groups might need reconsideration, as our study indicates that teachers can actively encourage cross-cultural learning.
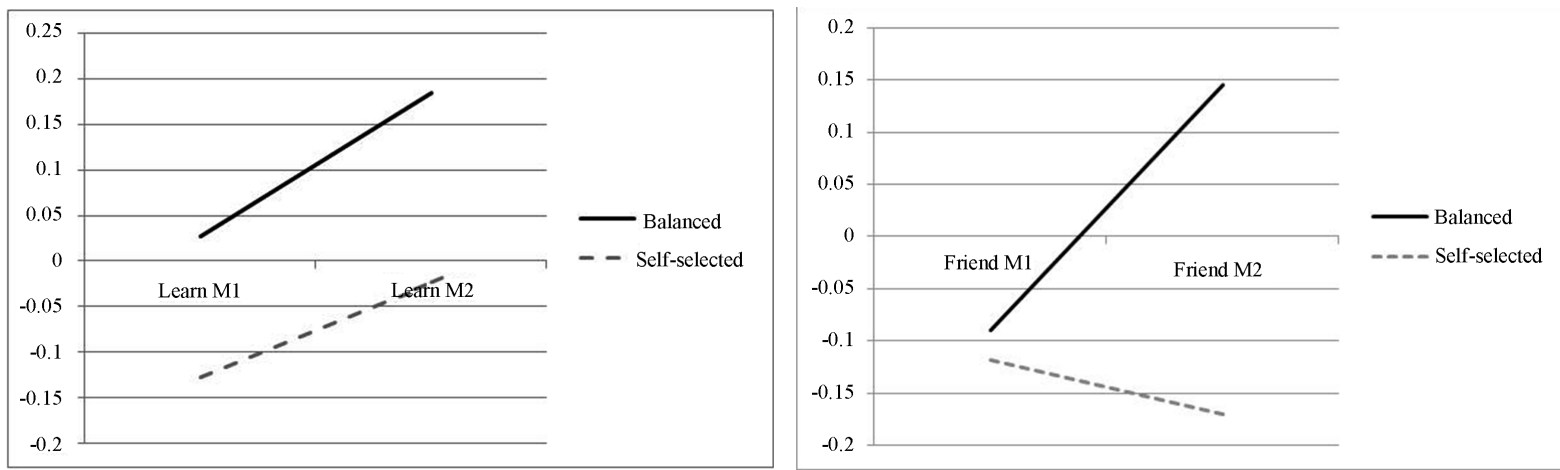

Figure 5. E-I index of culture in friendships and learning (pre-post test). 


\section{Limitations \& Future Research}

Although this study was developed and designed with the highest care, there are several limitations. A first limitation of this research is that the social network analyses were self-survey instruments. However, a large body of research [19] [30] has found that SNA techniques provide a robust predictor for actual social networks and learning outcomes, in particular given the high response rates in both conditions, and the longitudinal research design. A second limitation is that we did not conduct a fine-grained analysis of the actual learning interactions between students. However, given that the two conditions were similar at the start of the module and for most hypotheses moderate to strong effect sizes were found, our findings seem to suggest that group selection methods have a substantial influence on how students develop learning networks over time.

The dynamic use of SNA by measuring social learning and friendship interactions over time allows researchers many new angles in understanding social interaction processes amongst students. For example, experimenting with different compositions of groups based upon cultural backgrounds and friendships, different task-structures, group sizes, or different (group) assessment methods would allow a deeper insight into how teachers can actively encourage learning across learners and groups. Alternatively, using structural hole measures of Burt [14] and network closure and mixing students in groups based upon a combination of these indicators might maximise the reach and closeness within the social network. Furthermore, triangulation with qualitative research methods would further strengthen our understanding of the underlying mechanisms of why some students develop strong links with other students, while others remain relatively isolated. Preliminary findings of an in-depth qualitative study [35] in the balanced condition amongst five potential bridge builders seems to indicate that only two out of five students actually became bridge builders over time. For example, following one or two groups of students (e.g. based upon their unique position in the first social network) for a period of time and quantitatively and qualitatively measure their interactions within and outside their group would provide a fine-grained and enriched understanding how students from different cultural backgrounds develop, maintain and nurture friendship and learning links. Our results indicate that in mixed classrooms, the "automatic" preferred option for students to self-select their friends for group work may lead to a sub-optimal clustering of students along initial friendships and cultural backgrounds. Teachers can prevent this clustering by mixed students in diverse groups, thereby creating new opportunities for students to form bonding and bridging social capital.

\section{References}

[1] Hendrickson, B., Rosen, D. and Aune, R.K. (2011) An Analysis of Friendship Networks, Social Connectedness, Homesickness, and Satisfaction Levels of International Students. International Journal of Intercultural Relations, 35, 281. http://dx.doi.org/10.1016/j.ijintrel.2010.08.001

[2] Volet, S.E. and Jones, C. (2012) Cultural Transitions in Higher Education: Individual Adaptation, Transformation and Engagement. Advances in Motivation and Achievement, 17, 241. http://dx.doi.org/10.1108/S0749-7423(2012)0000017012

[3] Summers, M. and Volet, S. (2008) Students' Attitudes towards Culturally Mixed Groups on International Campuses: Impact of Participation in Diverse and Non-Diverse Groups. Studies in Higher Education, 33, 357. http://dx.doi.org/10.1080/03075070802211430

[4] Rienties, B., Heliot, Y. and Jindal-Snape, D. (2013) Understanding Social Learning Relations of International Students in a Large Classroom Using Social Network Analysis. Higher Education, 66, 489. http://dx.doi.org/10.1007/s10734-013-9617-9

[5] Rienties, B., Alcott, P. and Jindal-Snape, D. (2014) To Let Students Self-Select or Not: That Is the Question for Teachers of Culturally Diverse Groups. Journal of Studies in International Education, 18, 64. http://dx.doi.org/10.1177/1028315313513035

[6] Chapman, K.J., Meuter, M., Toy, D. and Wright, L. (2006) Can't We Pick Our Own Groups? The Influence of Group Selection Method on Group Dynamics and Outcomes. Journal of Management Education, 30, 557. http://dx.doi.org/10.1177/1028315313513035

[7] Sundstrom, E., McIntyre, M., Halfhill, T. and Richards, H. (2000) Work Groups: From the Hawthorne Studies to Work Teams of the 1990s and Beyond. Group Dynamics: Theory, Research, and Practice, 4, 44. http://dx.doi.org/10.1037/1089-2699.4.1.44

[8] Curşeu, P.L. and Pluut, H. (2011) Student Groups as Learning Entities: The Effect of Group Diversity and Teamwork Quality on Groups' Cognitive Complexity. Studies in Higher Education, 38, 87. http://dx.doi.org/10.1080/03075079.2011.565122 
[9] Zhou, Y., Jindal-Snape, D., Topping, K. and Todman, J. (2008) Theoretical Models of Culture Shock and Adaptation in International Students in Higher Education. Studies in Higher Education, 33, 63. http://dx.doi.org/10.1080/03075070701794833

[10] Rienties, B., Hernandez Nanclares, N., Jindal-Snape, D. and Alcott, P. (2013) The Role of Cultural Background and Team Divisions in Developing Social Learning Relations in the Classroom. Journal of Studies in International Education, 17, 322. http://dx.doi.org/10.1177/1028315312463826

[11] Decuyper, S., Dochy, F. and Van den Bossche, P. (2010) Grasping the Dynamic Complexity of Team Learning: An Integrative Model for Effective Team Learning in Organisations. Educational Research Review, 5, 111. http://dx.doi.org/10.1016/j.edurev.2010.02.002

[12] Harrison, N. and Peacock, N. (2010) Cultural Distance, Mindfulness and Passive Xenophobia: Using Integrated Threat Theory to Explore Home Higher Education Students' Perspectives on "Internationalisation at Home". British Educational Research Journal, 36, 877. http://dx.doi.org/10.1080/01411920903191047

[13] Kim, Y.Y. (2001) Becoming Intercultural: An Integrative Theory of Communication and Cross-Cultural Adaption. Sage, Thousand Oaks, California.

[14] Burt, R.S. (1992) Structural Holes: The Social Structure of Competition. Harvard University Press, Cambridge.

[15] Rienties, B., Hernandez Nanclares, N., Hommes, J. and Veermans, K. (2014) The Design, Experience and Practice of Networked Learning, In: Hodgson, V., De Laat, M., McConnell, D. and Ryberg, T., Eds., The Design, Experience and Practice of Networked Learning, Springer, Dordrecht, 127-148. http://dx.doi.org/10.1007/978-3-319-01940-6 7

[16] Neri, F. and Ville, S. (2008) Social Capital Renewal and the Academic Performance of International Students in Australia. Journal of Socio-Economics, 37, 1515. http://dx.doi.org/10.1016/j.socec.2007.03.010

[17] Curşeu, P.L., Janssen, S. and Raab, J. (2012) Connecting the Dots: Social Network Structure, Conflict, and Group Cognitive Complexity. Higher Education, 63, 621. http://dx.doi.org/10.1007/s10734-011-9462-7

[18] Rienties, B. and Nolan, E.-M. (2014) Understanding Friendship and Learning Networks of International and Host Students Using Longitudinal Social Network Analysis. International Journal of Intercultural Relations. http://dx.doi.org/10.1016/j.ijintrel.2013.12.003

[19] Katz, N., Lazer, D. and Arrow, H.N. (2004) Contractor, Network Theory and Small Groups. Small Group Research, 35, 307. http://dx.doi.org/10.1177/1046496404264941

[20] Hernandez Nanclares, N. Rienties, B. and Van den Bossche, P. (2012) Learning at the Crossroads of Theory and Practice. In: Van den Bossche, P., Gijselaers, W.H. and Milter, R.G., Eds., Learning at the Crossroads of Theory and Practice, Springer, Dordrecht, 157-175.

[21] Coleman, J.S. (1988) Social Capital in the Creation of Human Capital. American Journal of Sociology, 94, S95-S120. http://dx.doi.org/10.1086/228943

[22] Lin, N. (2001) Theories of Capital In: Lin, N., Cook, K.S. and Burt, R.S., Eds., Social Capital: Theory and Research, Transaction Publisher, New Brunswick, 3-18. http://dx.doi.org/10.1017/CBO9780511815447.002

[23] Gargiulo, M. and Benassi, M. (2000) Trapped in Your Own Net? Network Cohesion, Structural Holes, and the Adaptations of Social Capital. Organization Science, 11, 183-196. http://dx.doi.org/10.1287/orsc.11.2.183.12514

[24] Reagans, R. and McEvily, B. (2003) Network Structure and Knowledge Transfer: The Effects of Cohesion and Range. Administrative Science Quarterly, 48, 240-267. http://dx.doi.org/10.2307/3556658

[25] Daly, A.J. and Finnigan, K.S. (2010) A Bridge between Worlds: Understanding Network Structure to Understand Change Strategy. Journal of Educational Change, 11, 111-138. http://dx.doi.org/10.1007/s10833-009-9102-5

[26] Moolenaar, N.M., Sleegers, P.J.C. and Daly, A.J. (2012) Teaming Up: Linking Collaboration Networks, Collective Efficacy, and Student Achievement. Teaching and Teacher Education, 28, 251-262. http://dx.doi.org/10.1016/j.tate.2011.10.001

[27] Putnam, R.D. (2001) Bowling Alone: The Collapse and Revival of American Community. Simon \& Schuster, New York.

[28] Rienties, B., Johan, N. and Jindal-Snape, D. (2014) A Dynamic Analysis of Social Capital Building of International and UK Students. British Journal of Sociology of Education. http://dx.doi.org/10.1080/01425692.2014.886941

[29] Giuliani, E. (2013) Clusters, Networks and Firms' Product Success: An Empirical Study. Management Decision, 51, 1135-1160. http://dx.doi.org/10.1108/MD-01-2012-0010

[30] Hommes, J., et al. (2012) Visualising the Invisible: A Network Approach to Reveal the Informal Social Side of Student Learning. Advances in Health Sciences Education, 17, 743-757. http://dx.doi.org/10.1007/s10459-012-9349-0

[31] House, R.J., Hanges, P.J., Javidan, M., Dorfman, P.W. and Gupta, V. (2004) Culture, Leadership and Organizations: The GLOBE Study of 62 Societies. Sage Publications, Inc., Thousand Oaks. 
[32] Gašević, D., Zouaq, A. and Janzen, R. (2013) “Choose Your Classmates, Your GPA Is at Stake!”: The Association of Cross-Class Social Ties and Academic Performance. American Behavioral Scientist.

[33] Wassermann, S. and Faust, K. (1994) Social Network Analysis: Methods and Applications. Cambridge University Press, Cambridge. http://dx.doi.org/10.1017/CBO9780511815478

[34] Krackhardt, D. and Stern, R.N. (1988) Informal Networks and Organizational Crises: An Experimental Simulation. Social Psychology Quarterly, 51, 123-140. http://dx.doi.org/10.2307/2786835

[35] Rienties, B., Johan, N. and Jindal-Snape, D. (2014) Bridge Builders and Isolated Students: A Mixed Method Longitudinal Study of International and Host Students (Submitted). 